\title{
Metal-based phosphorus dendrimers as novel nanotherapeutic strategies to tackle cancers: A concise overview
}

\section{Article Type:}

\begin{tabular}{lll} 
COPINION & $\varnothing$ PRIMER & $\odot$ OVERVIEW \\
\hline$\odot$ ADVANCED REVIEW & $\varnothing$ FOCUS ARTICLE & $\varnothing$ SOFTWARE FOCUS
\end{tabular}

\section{Authors:}

\begin{tabular}{l} 
First author \\
Liang Chen, ${ }^{1}$ Laboratoire de Chimie de Coordination du CNRS, 205 route de Narbonne, \\
BP 44099, 31077 Toulouse Cedex 4, France; ${ }^{2}$ LCC-CNRS, Université de Toulouse, CNRS, \\
Toulouse, France, ${ }^{3}$ State Key Laboratory for Modification of Chemical Fibers and \\
Polymer Materials, College of Chemistry, Chemical Engineering and Biotechnology, \\
Donghua University, Shanghai 201620, PR China liangchen_cl@yeah.net \\
\hline Second author* \\
Serge Mignani, ${ }^{*} 0000-0002-1383-5256,{ }^{4}$ Department of Pharmacy, Zhengzhou Railway \\
Vocational \& Technical College, Zhengzhou, 450018, China; ${ }^{5}$ Université Paris Descartes, \\
PRES Sorbonne Paris Cité, CNRS UMR 860, Laboratoire de Chimie et de Biochimie \\
Pharmacologiques et Toxicologique, 45, rue des Saints Peres, 75006 Paris, France; ${ }^{6}$ \\
CQM - Centro de Química da Madeira, MMRG, Universidade da Madeira, Campus da \\
Penteada, $9020-105$ Funchal, Portugal; ${ }^{7}$ Glycovax Pharma, 424 Guy Street, Suite 202, \\
Montreal, Quebec, Canada H3J 1S6, serge.mignani@ parisdescartes.fr \\
\hline Third author \\
Anne-Marie Caminade, 0000-0001-8487-3578, ${ }^{1}$ Laboratoire de Chimie de Coordination \\
du CNRS, 205 route de Narbonne, BP 44099, 31077 Toulouse Cedex 4, France; ${ }^{2}$ LCC- \\
CNRS, Université de Toulouse, CNRS, Toulouse, France, anne-marie.caminade@lcc- \\
toulouse.fr \\
\hline Fourth author* \\
Jean-Pierre Majoral,* 0000-0002-0971-817X, ${ }^{1}$ Laboratoire de Chimie de Coordination \\
du CNRS, 205 route de Narbonne, BP 44099, 31077 Toulouse Cedex 4, France; ${ }^{2}$ LCC- \\
CNRS, Université de Toulouse, CNRS, Toulouse, France; ${ }^{4}$ Department of Pharmacy, \\
Zhengzhou Railway Vocational \& Technical College, Zhengzhou, 450018, China, jean- \\
pierre.majoral@lcc-toulouse.fr
\end{tabular}

\section{Abstract}

Several metal-based phosphorus dendrimers were prepared. The first series developed by us was the $\mathrm{Cu}(\mathrm{II})$ series. In this series, the most potent is the third generation-Cu(II) showing original mechanism of action with activation of the pro-apoptotic Bax protein. To our knowledge, it is the first example of nanoparticles displaying Bax protein activation and then cell death through 
apoptosis process. Interestingly, this dendritic-Cu(II) complex showed synergistic effect with doxorubicin. Based on these interesting antiproliferative activities, we developed $\mathrm{Au}(\mathrm{III})$-conjugated phosphorus dendrimers. The most potent is the third generation-Au(III) dendrimer which represents also a new and promising first-in-class anti-proliferative agent against both solid and liquid tumour cell lines. Then, in order to analyse the influence of the metal moiety distribution of $\mathrm{Cu}(\mathrm{II})$ and $\mathrm{Au}$ (III) on the surface of dendrimers, mix $\mathrm{Cu}(\mathrm{II})$-Au(III)-conjugated phosphorus dendrimers were also prepared and tested as antiproliferative agents.

\section{Graphical/Visual Abstract and Caption}

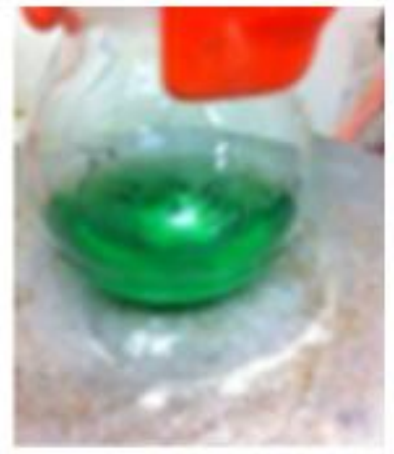

$\mathrm{Cu}(\mathrm{II})$-based phosphorus dendrimer

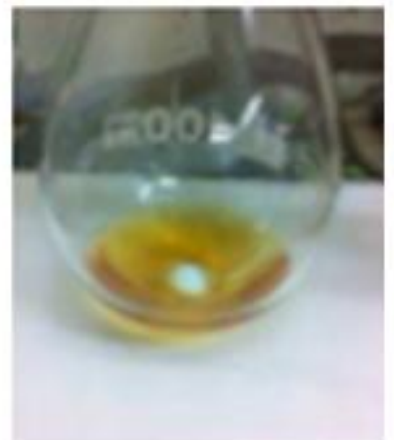

$\mathrm{Au}(\mathrm{III})$-based phosphorus dendrimer

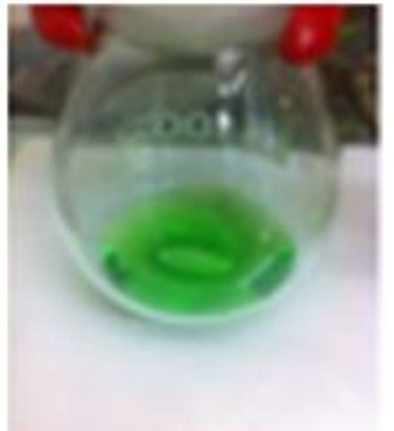

Dual Cu(II)-Au(III)based phosphorus dendrimer

Different metallo-based third generation dendrimers having anti-proliferative activity. The coloration of the solution is related to the metal (Cu(II) and $\mathrm{Au}(\mathrm{III}))$ and the mix of the same metals.

Introduction

Although considerable progress has been made in cancer therapy, the complete cure and eradication of cancers in general remain one of the greatest challenges today for the pharmaceutical industry. One of the hurdles is the drug resistance induced by chemotherapeutics, causing therapeutic failure, as well as the systemic toxicity of conventional anticancer drugs (Holohan, Van Schaeybroeck, Longley, \& Johnston, 2013)To address the toxicity, poor drug bioavailability (PK/PD) and non-target specificity of traditional anticancer drugs and to increase their therapeutic window (e.g., reduce dose and toxicity), the application of nanotechnology for drug delivery is widely expected to bring new hope for cancer treatment. Among the various nanotechnology-based drug delivery strategies, significant work has been done in past decades in the development of functionalized nanoparticles, such as liposomes, nanomicelles, metals, organic and polymeric nanoparticles (e.g., dendrimers), and peptide-based nanoparticles. Caelyx (pegylated liposome encapsulating doxorubicin), which is used against metastatic breast cancer, Myocet and Abraxane (albumin nanoparticles complexing paclitaxel) are the main nanoparticles developed in oncology (Chauhan \& Jain, 2013). Nanoparticle-based drug delivery (Petros \& De Simone, 2010) represents a gold standard for site-specific therapeutics (Blanco, Shen \& Ferrari, 2015). The local anti-cancer drug concentration should be achieved at the tumour site through enhanced permeation and retention (EPR), but this effect has recently been challenged, mainly based on the highly heterogeneity associated with tumours and with the EPR effect itself (Allen, 2016). 
Another important domain of research that few examples described to date is the development of nanoparticles as nanodrugs (active, per se). The expected clinical advantages of the use of nanoengineering are preferential organ (site specific), preferential tissue distribution, improvement of transport across biological barriers, and consequently, maximizing the therapeutic efficacy (Ferrari, 2005). Generally speaking, toxicity in general, and immunotoxicity in particular, is a very important point to be evaluated and addressed by manipulation of particle physicochemical properties (Bourzac, 2012).

Within the myriad of nanoparticles developed in nanomedicine, dendrimers, which are highly monodisperse, branched (multi directional branches), star-shaped macromolecules with nanometerscale dimensions and a carefully tailored architecture, have gained a broad range of applications, including medicinal applications (Rolland, Turrin, Caminade. \& Majoral, 2009) (Kannan, Nance, Kannan \& Tomalia, 2014), mainly in drug delivery (Medina \& El-Sayed, 2009) (Mignani \& Majoral, 2013) (Mignani, Rodrigues, Tomas, Zablocka, Shi, Caminade \& Majoral, 2018). The drugs can be encapsulated within the dendrimer interior or conjugated onto the dendrimer surface. The four main parts of a dendrimer are: the core, end-groups (surface groups), branches and internal cavities able to encapsulate drugs (Figure 1 ). The interior layers define the generations (Gn), where $n$ is 1,2 , 3 , 4, etc. The Figure 1 shows 2D chemical structure of phosphorus dendrimers developed by J-P. Majoral and A. Caminade (vide infra).

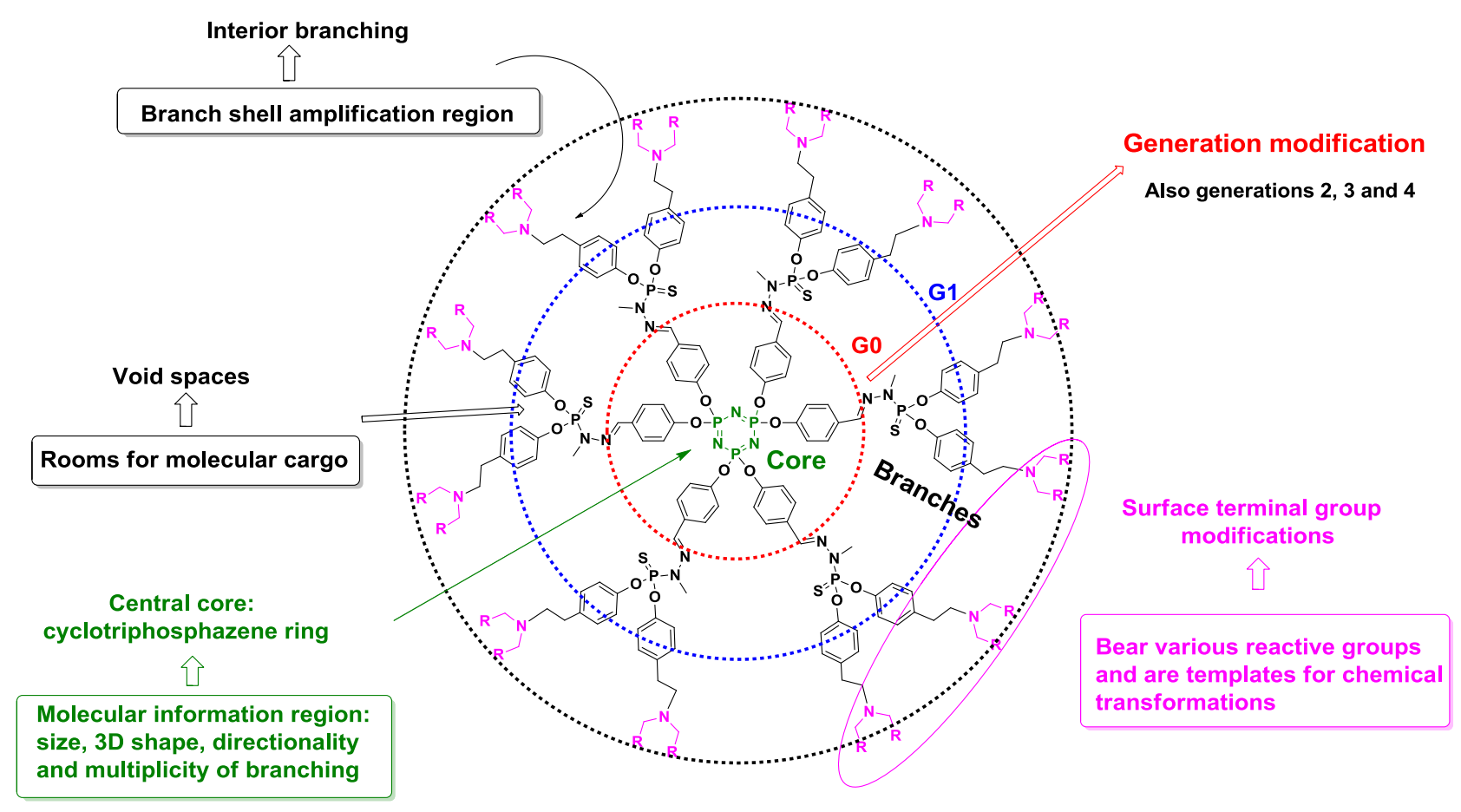

Figure 1. 2D chemical structure of phosphorus dendrimers.

In 2012, two pivotal Phase III trials for the treatment of bacterial vaginosis with VivaGel ${ }^{\circledR}$ (SPL7013 Gel, astodrimer sodium) were started by Starpharma Holdings Limited, Melbourne, Australia. This polyanionic G4-poly(L-lysine)-type nanoparticle has 32 naphthalene disulfonate groups on the surface. Starpharma has recently received FDA Phase III approval. Also, Starpharma has recently advanced from Phase I to Phase II with a poly(lysine)dendrimer-based nanocarrier encapsulating docetaxel (DEP ${ }^{\circledR}$ docetaxel). This nano-carrier system showed superior anticancer activities against 
breast, prostate, lung and ovarian tumours versus chemotherapy. Importantly, patients treated with $D{ }^{\circledR}$ docetaxel showed lower side effects compared with conventional docetaxel formulations. Thus, no neutropenia side effects or life-threatening toxicity have been seen (Starpharma).

In this minireview, we survey another important application of dendrimers in oncology: the preparation of original metal-based phosphorus dendrimers as novel anticancer agents.

\section{Metallo-based pharmaceuticals at a glance}

Today, chemotherapy remains the main systemic approach for the treatment of cancers, and there are over 50 chemotherapy drugs used to treat over 200 different types of cancer (Chemotherapy Procedure). The majority of the currently approved clinical drugs are organic compounds ( 99\%), and very low percentages of metal-containing drugs have been developed. However, in the domain of cancer chemotherapy, platinum coordination compounds, such as cisplatin, oxaliplatin and carboplatin, are used as effective anti-tumour compounds, but with drawbacks, such as resistance and severe toxicity. In addition, other metals have been used, including polynuclear Pt complexes and Pt(IV) complexes as prodrugs, Ru(II/III)-, Au(I/III)-, Ti(IV)-, V(IV/V)-, Ga(III)-, Fe(II/III)-, Cu(I/II)- and $\mathrm{Zn}(\mathrm{II})$-based compounds. Figure 2 shows the chemical structures of several metallocene pharmaceuticals (El Kazzouli, El Brahmi, Mignani, Bousmina, Zablocka \& Majoral, 2012).

'Classical' Pt(II) and Pt(IV) complexes

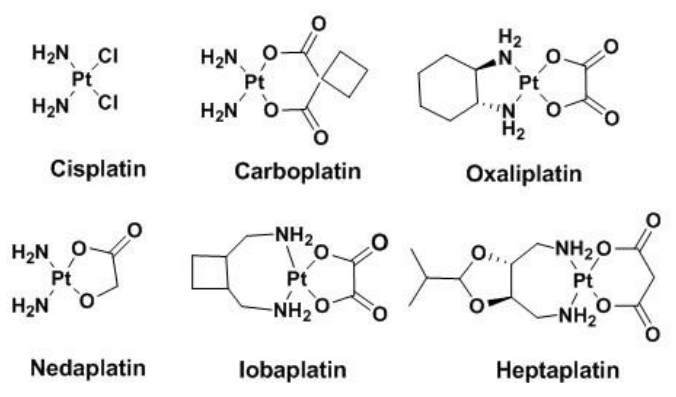

\section{Selected families of copper complexes}

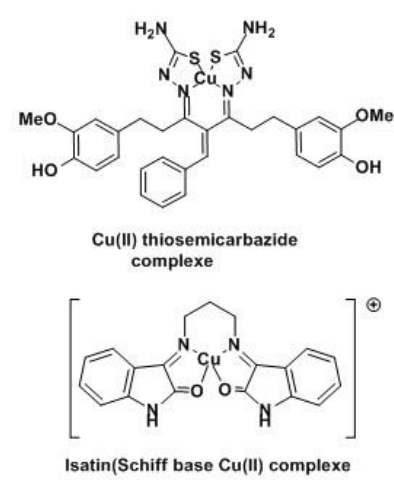

\section{Chemical structure of Ti- and Fe-based metallocene pharmaceuticals}
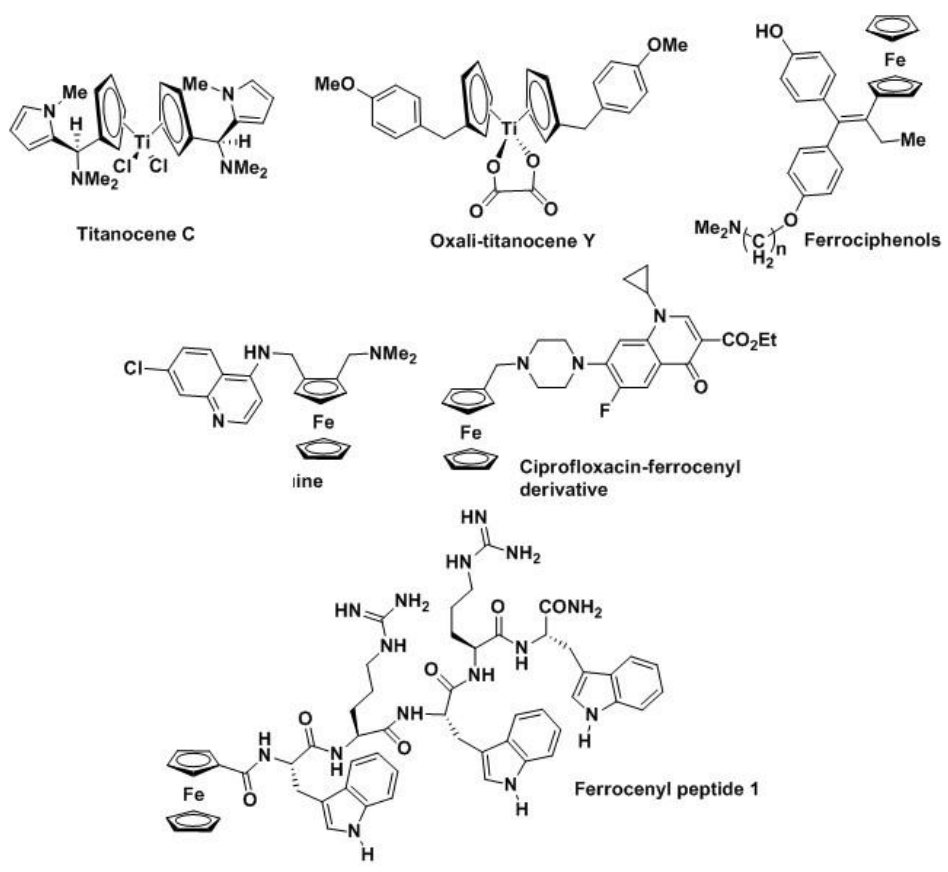

[(4,7-dimethyl-1,10-phenanthroline)(glicinate)Cu(II)
complexe

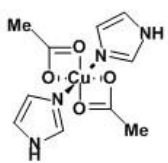

Trans-bis(acetato)bis(imidazole)]Cu(II)
complexe

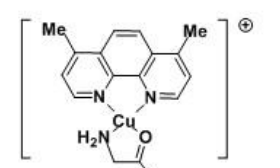

Figure 2. Chemical structure of several metallo-based pharmaceuticals.

In a general point of view, dendrimers represent a powerful alternative approach to the delivery methods for metallodrugs Up to date, few examples described the preparation of dendrimers which were conjugated with metals to be used in nanomedicine. Cisplatin is the most investigated 
metallodrug and it was loaded with dendrimers using two different coordination strategies: 1) $\left(\mathrm{NH}_{2}\right)_{2}$-Pt-(O-dendrimer) 2 ; and $(\mathrm{Cl})_{2}$-Pt-(NH-dendrimer) 2 (El Kazzouli, El Brahmi, Mignani, Bousmina, Zablocka \& Majoral, 2012). Generally speaking, dendrimer-metallodrug conjugates displayed higher solubility, higher potency against sensitive and resistant tumour cell lines versus the corresponding metallodrugs. Interestingly, in some cases, metallodendrimers appear to operate via a different mechanism of action to native metallodrug (Kim, Yoon, Kim, Wang, Ishii, Kim, \& Jang, 2009). Consequently, the development of metallo-dendrimers opens new avenues in the search of novel antitumor agents as best-in-class or as first-in-class.

\section{Why biocompatible phosphorus dendrimers?}

Biocompatible phosphorus dendrimers based on a cyclotriphosphazene core (Figure 1) (Slany, Bardaji, Casanove, Caminade, Majoral \& Chaudret, 1995) represent a versatile platform in drug delivery (e.g., drugs and gene transfection delivery), and as a drug, per se (Caminade et al, 2015), as well as in imaging applications (Sourdon, Gary-Bobo, Maynadier, Garcia, Majoral, Caminade, Mongin \& Blanchard-Desce, 2019) due to the possible high level of control over their architectural design, allowing for the tunable control of sizes and shapes (cores and interiors) (Caminade et al., 2015). In addition, tunable surface functionality represents a strong advantage (Mignani, El Kazzouli, Bousmina \& Majoral, 2013b). Thus, biocompatible phosphorus dendrimers have been developed by Jean-Pierre Majoral and Anne-Marie Caminade for several diverse important therapeutic applications, such as oncology, prevention of neurodegenerative diseases, inflammation, and HIV therapeutic domain, among others (Caminade, Turrin \& Majoral, 2018).

Phosphorus dendrimers have the strong advantage of being biocompatible (e.g., low systemic toxicity, good PK/PD profile, etc.), are easy to prepare on a large scale ( $>0.5 \mathrm{~kg}$, generation 1-4) with high quality, and importantly, can be prepared under GMP (good manufacturing practices) grade, which is mandatory for entering into clinical phases. In addition, beside the classic intravenous route, phosphorus dendrimers can also be administered via several other routes, such as orally or transdermal, and through inhalation, nasal and ophthalmic routes (Mignani, El Kazzouli, Bousmina \& Majoral, 2013a).

Our objective was to develop first-in-class metallo-based phosphorus dendrimers as anticancer agents. The selected strategy is based on a phenotypic screening strategy using the ability to alter a cell's phenotype, and consequently, does not rely on knowing the identity of the specific drug target.

\section{Design of biocompatible multivalent $\mathrm{CU}(\mathrm{II}), \mathrm{Fe}$ (II) and $\mathrm{Au}(\mathrm{III})$-conjugated phosphorus dendrimers}

Our goal was to examine the anti-proliferative activity of biocompatible phosphorus multivalent dendrimers of generations 1-3 bearing a cyclophosphazene core as a scaffold and complexing metals like copper (II) and gold (III). Three different series, within three different generations (G1, G2 and G3) were prepared, bearing bidentate chelators, and were evaluated with $N$-(pyridin-2ylmethylene)ethanamine (named NN) for dendrimers of $1 \mathrm{Gn}(\mathrm{n}=1-3), \quad \mathrm{N}$-(di(pyridin-2$\mathrm{yl}$ )methylene)ethanamine for dendrimers of $2 \mathrm{Gn} \quad(\mathrm{n}=1$ and 3) and 2-(2methylenehydrazinyl)pyridine for dendrimers $3 G n(n=1-3)$. The number of terminal groups on the surface of the dendrimer was 12,24 and 48 for dendrimers of generation 1,2 and 3, respectively 
(Figure 3). Dendrimer synthesis was accomplished by a straightforward synthetic pathway (El Brahmi et al., 2013).
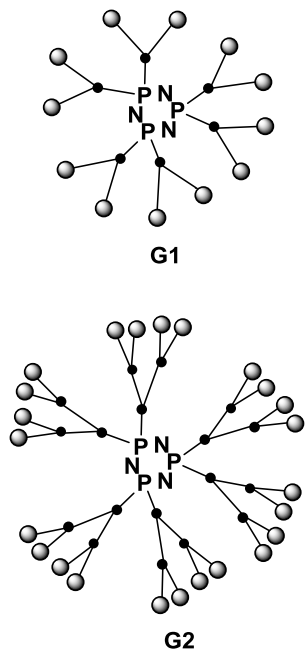

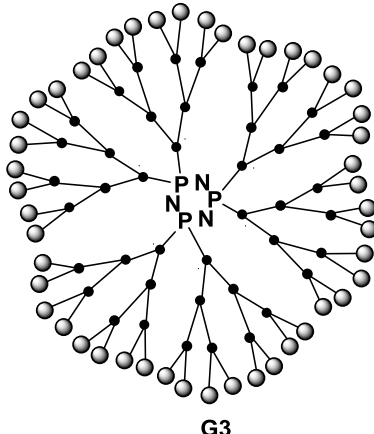

G3

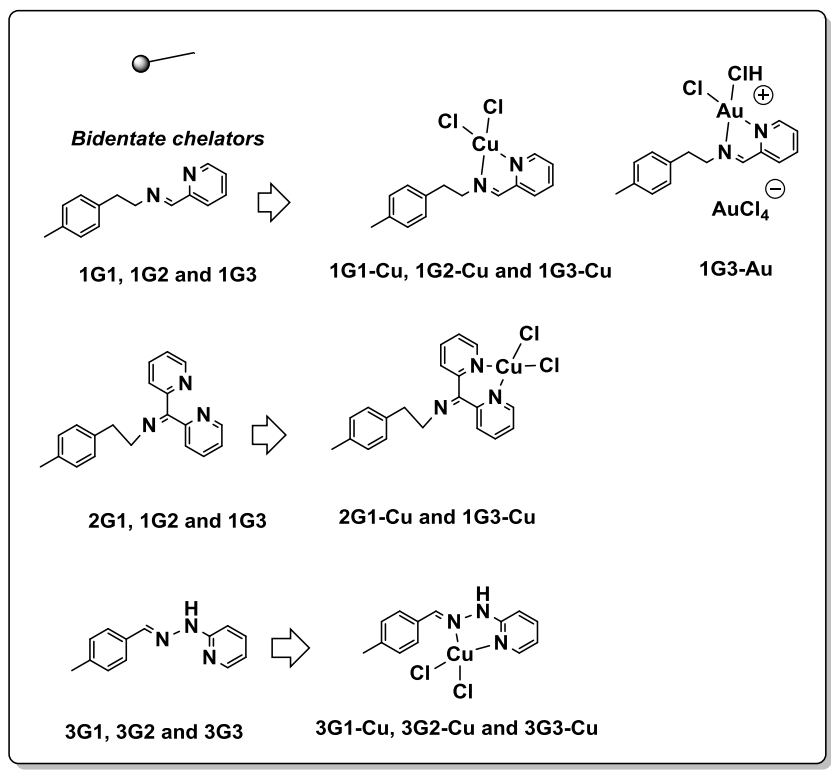

Figure 3. Two-dimensional schematic general structure of multivalent phosphorus dendrimers prepared.

Our attention was first oriented toward copper for the following reasons: 1) nowadays, few families of copper complexes have been studied in vitro and in vivo, and 2) the advantage to overcome inherent/acquired resistance to cisplatin (Kartalou \& Essigmann, 2001). Based on a classical phenotypic screening, the different multivalent chemical series were tested against KB (epidermal carcinoma) and leukaemia HL6O (promyelocytic) tumour cells, as representative markers for anticancer activity. Clearly, the most potent series is the first series with ( $N$-(pyridin-2ylmethylene)ethanamine as a chelator, no matter which tumour cell lines were used, suggesting a strong impact of the terminal moiety types on the anti-proliferative activities. The inhibition of cell proliferation at $1 \mu \mathrm{M}$ (KB and HL60) ranged between $\sim 20 \%$ and $~ 80 \%$ for 1G1-Cu, 1G2-Cu and 1G3$\mathrm{Cu}$, and between $\sim 30 \%$ and $\sim 40 \%$ for $1 \mathrm{G} 1,1 \mathrm{G} 2$ and 1G3. Interestingly, for the Cu-based dendrimers, the inhibition of cell proliferation increased linearly with the number of terminal groups (12-48), indicating that each terminal group participates in the global activity. The most effective antiproliferative activities against both KB and HL60 were obtained with 1G3-CU (48 terminal groups, Figure 4). The inhibition of cell proliferation (at $1 \mu \mathrm{M}$ ) for $1 \mathrm{G3}$ and $1 \mathrm{G3}-\mathrm{Cu}$ were $\sim 40 \%$ and $\sim 80 \%$, respectively (El Brahmi et al., 2013). An explanation of the better activity of the $1 \mathrm{Gn}$-Cu family compared to the other families is the better stability of the complexes in biological conditions, as shown by EPR (electron paramagnetic resonance) (Ottaviani et al., 2014). 

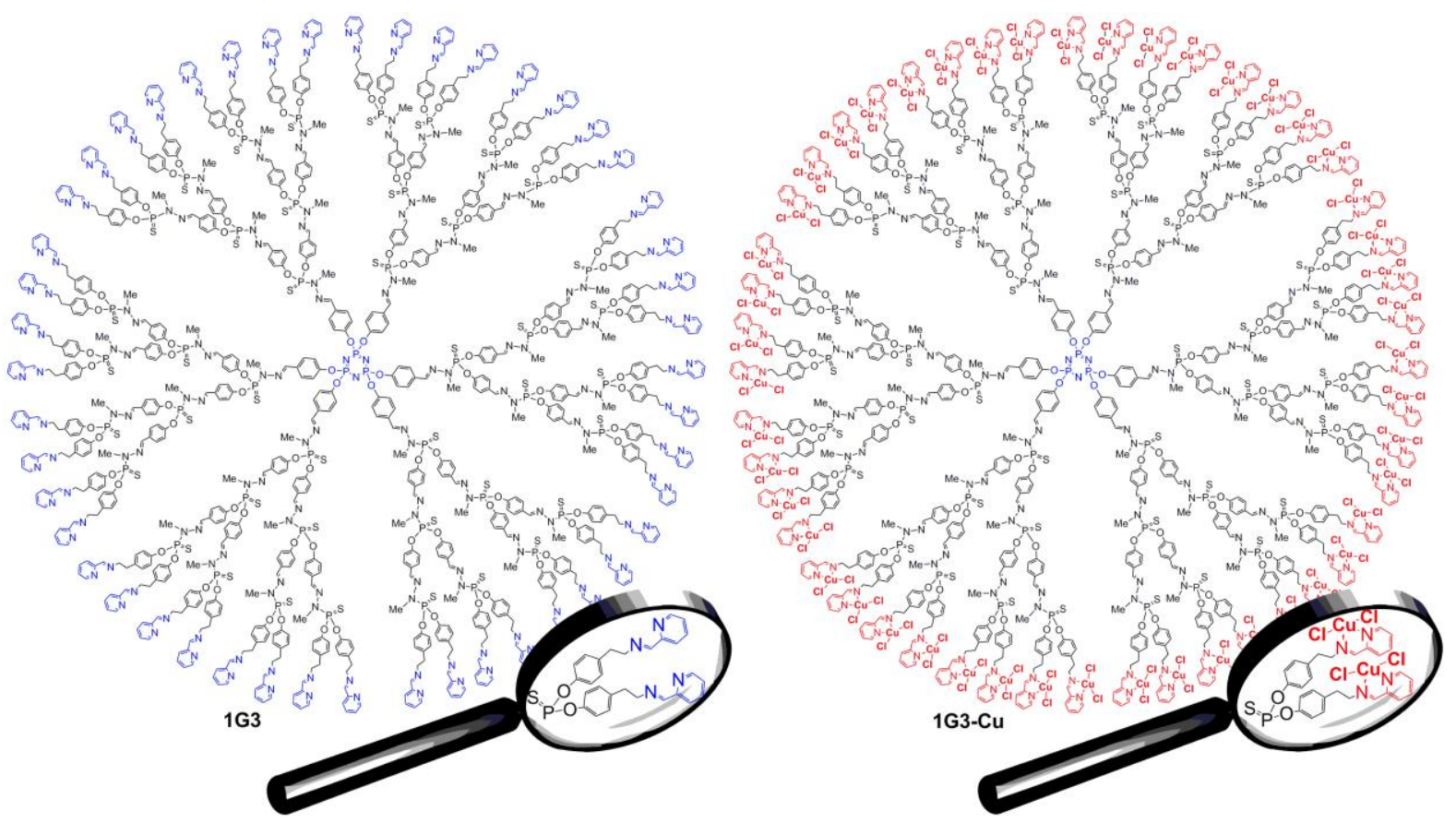

Figure 4. Two-dimensional chemical structure of plain $1 \mathrm{G} 3$ and $1 \mathrm{G3}-\mathrm{Cu}$ dendrimers.

Next, we tested $1 \mathrm{G} 3$ and $1 \mathrm{G} 3-\mathrm{Cu}$ against a representative panel of solid and liquid tumour cell lines, as well as non-cancer cells, including human primary glioblastoma U87, ovarian carcinoma OVCAR8, hormone-responsive breast cancer MCF7, human colon cancer HCT116, leukaemia promyelocytic HL60, epidermal carcinoma KB, quiescent endothelial progenitor Cyprinus carpio EPC and proliferative human lung fibroblasts MCR5 (Figure 5).

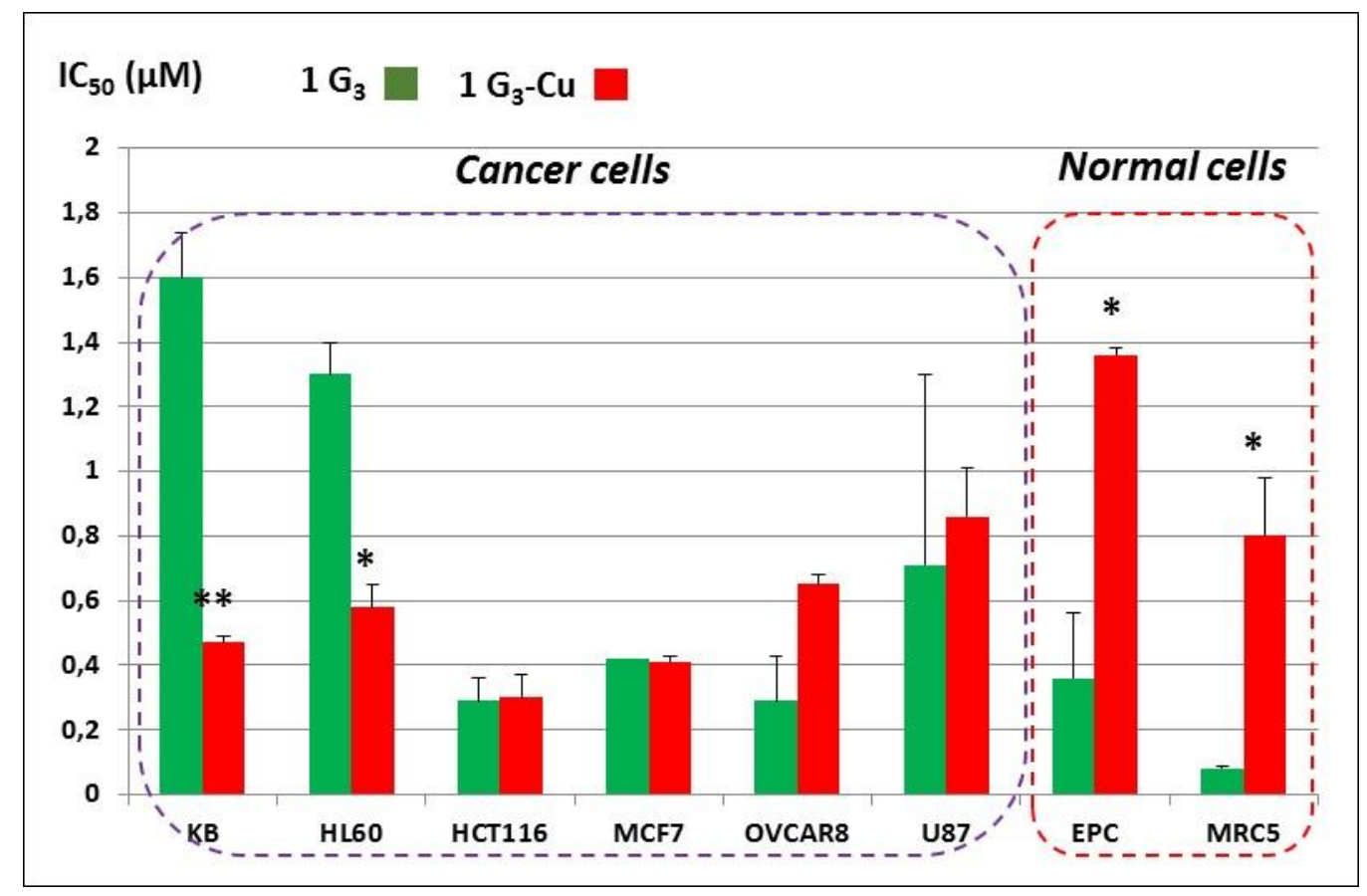

Figure 5. Growth inhibition effects of $1 \mathrm{G} 3$ and 1G3-Cu upon a panel of tumor cells and normal cells. Data are expressed as the mean $\pm \mathrm{SE}$ of $\mathrm{IC}_{50}$ calculated for two individual determinations in duplicate. ${ }^{*}: p<0.05,{ }^{* *}: p<0.01$ 
As depicted in Figure 5, in KB and HL60 cell lines, $1 \mathrm{G3}$ and 1G3-Cu displayed $\mathrm{IC}_{50} \mathrm{~S}$ of $1.2-1.6$ and $\sim 0.4-0.6 \mu \mathrm{M}$, respectively. The plain dendrimer $1 \mathrm{G} 3$ and the metallo-dendrimer 1G3-Cu showed similar anti-proliferative potency of $\sim 0.2-0.6 \mu \mathrm{M}$ against HCT116, MCF7 and OVCAR8 and similar potency $(\sim 0.7-0.8 \mu \mathrm{M})$ against $\mathrm{U} 87$ cell lines. Remarkably, complexation of $1 \mathrm{G} 3$ with $\mathrm{Cu}(\mathrm{II})$ considerably increased the safety profile of $1 \mathrm{G} 3-\mathrm{Cu}$ compared with $1 \mathrm{G} 3$. The $\mathrm{IC}_{50} 1 \mathrm{G} 3-\mathrm{Cu} / \mathrm{IC}_{50} 1 \mathrm{G} 3$ ratio is, respectively, 4 and 10 for EPC and MCR5. IC $\mathrm{I}_{50}$ is $\sim 0.08$ for $1 \mathrm{G} 3$ versus $\sim 0.8$ for $1 \mathrm{G} 3$-Cu with MCR5, and $\sim 0.36$ for $1 \mathrm{G} 3$ and 1.39 for $1 \mathrm{G3}-\mathrm{Cu}$ with EPC, which are referred to as 'safety' cell lines.

In order to evaluate the frame of the cytotoxicity profile of $1 \mathrm{G} 3$ and $1 \mathrm{G} 3-\mathrm{Cu}$, we tested these two dendrimers against cisplatin-sensitive and cisplatin-resistant cell lines. 1G3-Cu showed strong antiproliferative activities against cisplatin-resistant cell lines, such as A2780 resistant and SK-OV-3, compared to A270 and OVCAR8. Only 2-fold increase occurred in the $\mathrm{IC}_{50} \mathrm{~S}$. Note that $1 \mathrm{G} 3$ displayed no anti-proliferative activity against $\mathrm{A} 2780$, unlike cisplatin and $1 \mathrm{G} 3-\mathrm{Cu}$.

Then, we evaluated the cytotoxic effect of $1 \mathrm{G} 3$ and $1 \mathrm{G} 3-\mathrm{Cu}$ against cell lines over-expressing Pglycoprotein efflux pumps (P-gP) or a silenced mdr1 gene expression phenotype (Multi Drug Resistance, MDR). P-gP is expressed in many organs and physical barriers, including the gastrointestinal (GI) tract, blood-brain-barrier (BBB), kidney, liver, endothelium and placenta. Pglycoprotein acts as an efflux pump to pump materials, such as drugs, out of the cell and represents a good example of a clinically relevant drug transporter influencing, for instance, bioavailability, chemotherapy, effective tissue penetration (e.g., brain), and the adjustment of the dosing regimen (Amin, 2013). P-gp displays low affinity for ATP and high constitutive ATPase activity. P-gp also has a broad specificity for hydrophobic substrates, such as many chemotherapeutic drugs (e.g., Taxol, vincristine, vinblastine, actinomycin D, colchicines and daunorubicin) (Lehne, 2000). 1G3-Cu showed similar cytotoxic effects against tumours cell lines (HCT116, HL60 and MCF7) and their corresponding cell lines expressing P-gP or silenced mdr1 (HCT116 P-gP, HL60 P-gP and MCF7-mdr1). Consequently, 1G3-Cu is not recognized by P-gP nor mdr1, unlike $1 \mathrm{G} 3$.

Our attention was then turned to the influence of the metal type on the anti-proliferative activities. The Au(III)- and Fe(II)-based dendrimers (generation 3, 48 terminal groups) (Figure 6) have been tested against KB, HL60, EPC and MRC5 cell lines and safety ratio evaluated (Table 1). 


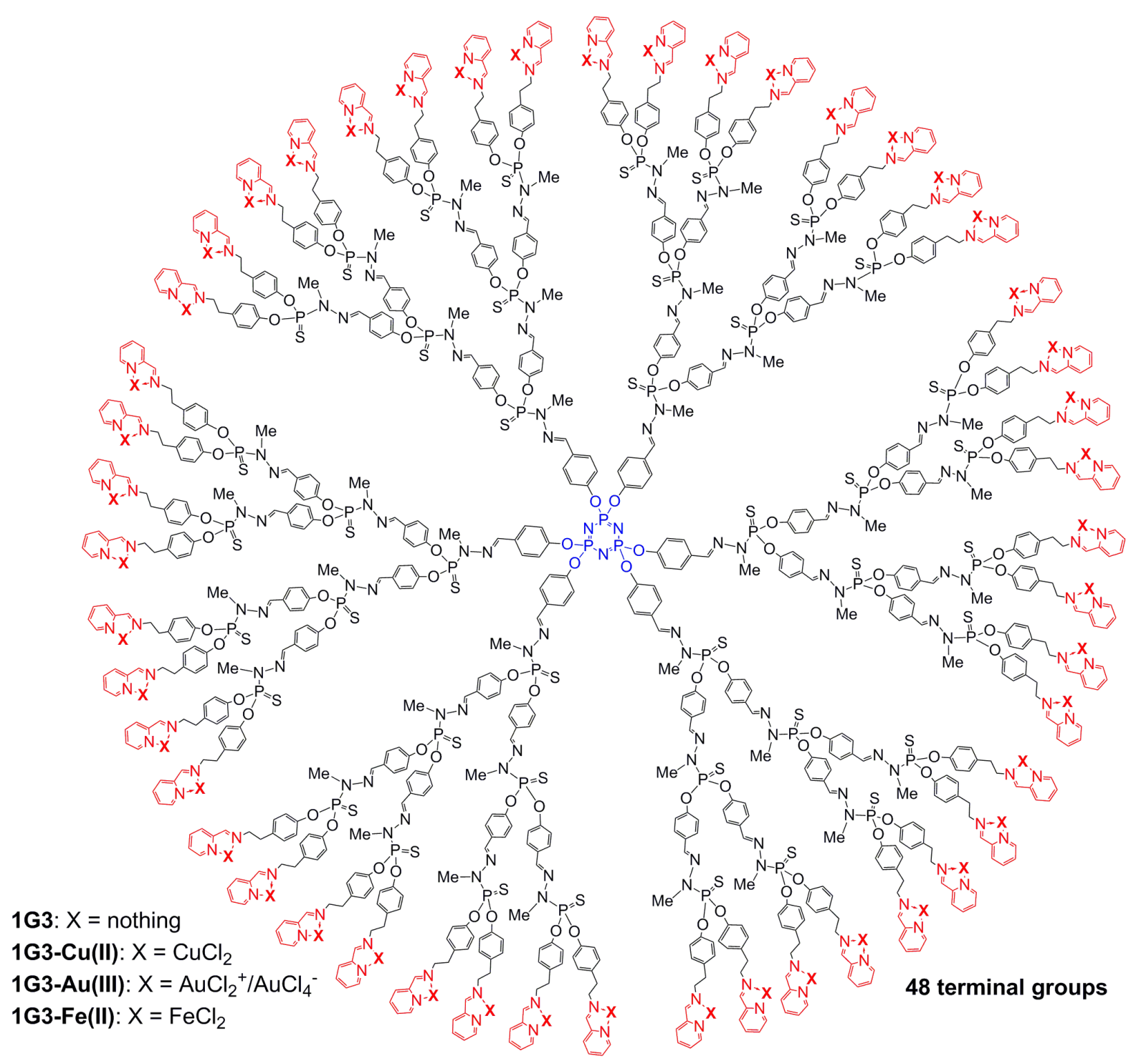

Figure 6. Two-dimensional chemical structure of 1G3-Cu(II), 1G3-Au(III) and 1G3-Fe(II) dendrimers

Table 1. Anti-proliferative activities of 1G3-Cu(II), 1G3-Au(III) and 1G3-Fe(II) dendrimers.

\begin{tabular}{|l|c|c|c|c|c|c|}
\hline \multicolumn{3}{|c|}{ IC $_{50}$ (nM) } & \multicolumn{2}{c|}{ Safety ratio } \\
\hline Dendrimer & KB & \multicolumn{1}{|c|}{ HL60 } & MRC5 & EPC & $\begin{array}{c}\text { EPC/KB and } \\
\text { EPC/HL60 }\end{array}$ & $\begin{array}{c}\text { MRC5/KB and } \\
\text { MRC5/HL60 }\end{array}$ \\
\hline 1G3-Fe(II) & $\begin{array}{l}6 \% \text { at } \\
1 \mu \mathrm{M}^{\mathrm{a}}\end{array}$ & $\begin{array}{l}0 \% \text { at } \\
1 \mu \mathrm{M}^{\mathrm{a}}\end{array}$ & NT & $15 \%$ at $1 \mu \mathrm{M}$ & & \\
\hline 1G3-Cu(II) & $470+/-20$ & $580+/-70$ & $470+/-20$ & $800+/-180$ & 1.7 and 1.4 & 1 and 0.8 \\
\hline 1G3-Au(III) & $7.5+/-7.5$ & $3.3+/-0.6$ & $12+/-5$ & $>1000$ & 133 and 303 & 1.6 and 3.6 \\
\hline
\end{tabular}

a: inhibition of cell proliferation at $1 \mu \mathrm{M}$ b: $I C_{50}(E P C) / I C_{50}(K B$ or $H L 60)$ c: IC $C_{50}(M R C 5) / I C_{50}(K B$ or HL60) 
As shown in Table 1, the replacement of $\mathrm{Cu}$ (II) by $\mathrm{Fe}(\mathrm{II})$ abolished the anti-proliferative activities, whereas the replacement by $\mathrm{Au}(\mathrm{III})$ increased considerably the anti-proliferative activity. 1G3-Au(III) showed $\mathrm{IC}_{50} \mathrm{~S}$ of $7.5 \mathrm{nM}$ and $3.3 \mathrm{nM}$ against $\mathrm{KB}$ and $\mathrm{HL60}$, respectively. Interestingly, the safety ratios $I_{50}(E P C) / I C_{50}$ (KB or HL60) and IC $C_{50}$ (MRC5)/IC $C_{50}$ (KB or HL60) of $A u(I I I)$ is better than those with $\mathrm{Cu}(\mathrm{II})$. Therefore, 1G3-Au(III) represents a very interesting new nanodrug against liquid and solid tumour cell lines at the $\mathrm{nM}$ anti-proliferative range.

\section{Design of original biocompatible multivalent dual $\mathrm{Cu}(\mathrm{II})-\mathrm{Au}(\mathrm{III})$-conjugated phosphorus dendrimers}

Based on the good and very good anti-proliferative activities of 1G3-Cu and 1G3-Au (Table 1), the next step was to analyse the influence of the metal moiety distribution of $\mathrm{Cu}(\mathrm{II})$ and $\mathrm{Au}$ (III) on the surface of $1 \mathrm{G} 3$ dendrimers. We focused on the preparation of nine $\mathrm{G} 3$ dendrimers bearing on the surface $\mathrm{Cu}(\mathrm{II})$ and $\mathrm{Au}(\mathrm{III})$, complexed with the bidentate chelators $\mathrm{N}$-(pyridin-2ylmethylene)ethanamine (named $\mathrm{NN}$ ), free $\mathrm{NN}$ and some PEG chains (11 $\mathrm{CH}_{2} \mathrm{CH}_{2} \mathrm{O}$ linkages) to evaluate the potential synergistic effect between $\mathrm{Au}(\mathrm{III})$ and $\mathrm{Cu}(\mathrm{II})$. PEG chains were selected to increase the water solubility (Mignani et al., 2017a). Figure 7 presents the construction of the different dual phosphorus dendrimers, and Table 2 shows the anti-proliferative activities of 1G3-Cu, 1G3-NN/PEG(1), 1G3-NN/PEG(2), 1G3-NN/PEG(3), 1G3-NN/PEG/Au(4), 1G3-NN/PEG/Au(5), 1G3NN/PEG/Au(6), 1G3-PEG/Au/Cu(7), 1G3-NN/PEG/Au/Cu(8), 1G3-PEG/Au(9) and 1G3-Au against KB and HL60 tumour cell lines and EPC quiescent cell lines. All of the dual dendrimers incorporate a stochastic number of functional group types on their respective surfaces. Interestingly, 1G3NN/PEG/Au(4), 1G3-NN/PEG/Au(5), 1G3-NN/PEG/Au(6), 1G3-PEG/Au/Cu(7), 1G3-NN/PEG/Au/Cu(8) and $1 \mathrm{G} 3-\mathrm{PEG} / \mathrm{Au}(9)$ displayed similar potency to $1 \mathrm{G} 3-\mathrm{Au}$ in view of the anti-proliferative activities against KB and HL60, no matter what the number of $A u(I I I)$ moieties introduced. No cumulative effect of $\mathrm{Cu}(\mathrm{II})$ was observed in the presence of $\mathrm{Au}(\mathrm{III})$ (1G3-PEG/Au/Cu(7), 1G3-NN/PEG/Au/Cu(8) versus 1G3-Au). Without $\mathrm{Cu}(\mathrm{II})$ or $\mathrm{Au}(\mathrm{III})$, no anti-proliferative activities were observed (1G3NN/PEG(1), 1G3-NN/PEG(2), 1G3-NN/PEG(3)). All of the dendrimers prepared displayed no activity against the EPC quiescent cell line. Interestingly, 1G3-Au and 1G3-PEG/Au(9) displayed very good anti-proliferative activities against the MCF7 human breast adenocarcinoma cell line and PC3 prostatic small cell carcinoma, with $\mathrm{IC}_{50} \mathrm{~S}$ of $6 \mathrm{nM}$ and $1.5 \mathrm{nM}$, and $2.5 \mathrm{nM}$ and $0.5 \mathrm{nM}$, respectively. The dual 1G3-PEG/Au/Cu(7) dendrimers showed $\mathrm{IC}_{50} \mathrm{~S}$ of $60 \mathrm{nM}$ and $13 \mathrm{nM}$ against MCF7 and PC3, respectively. 


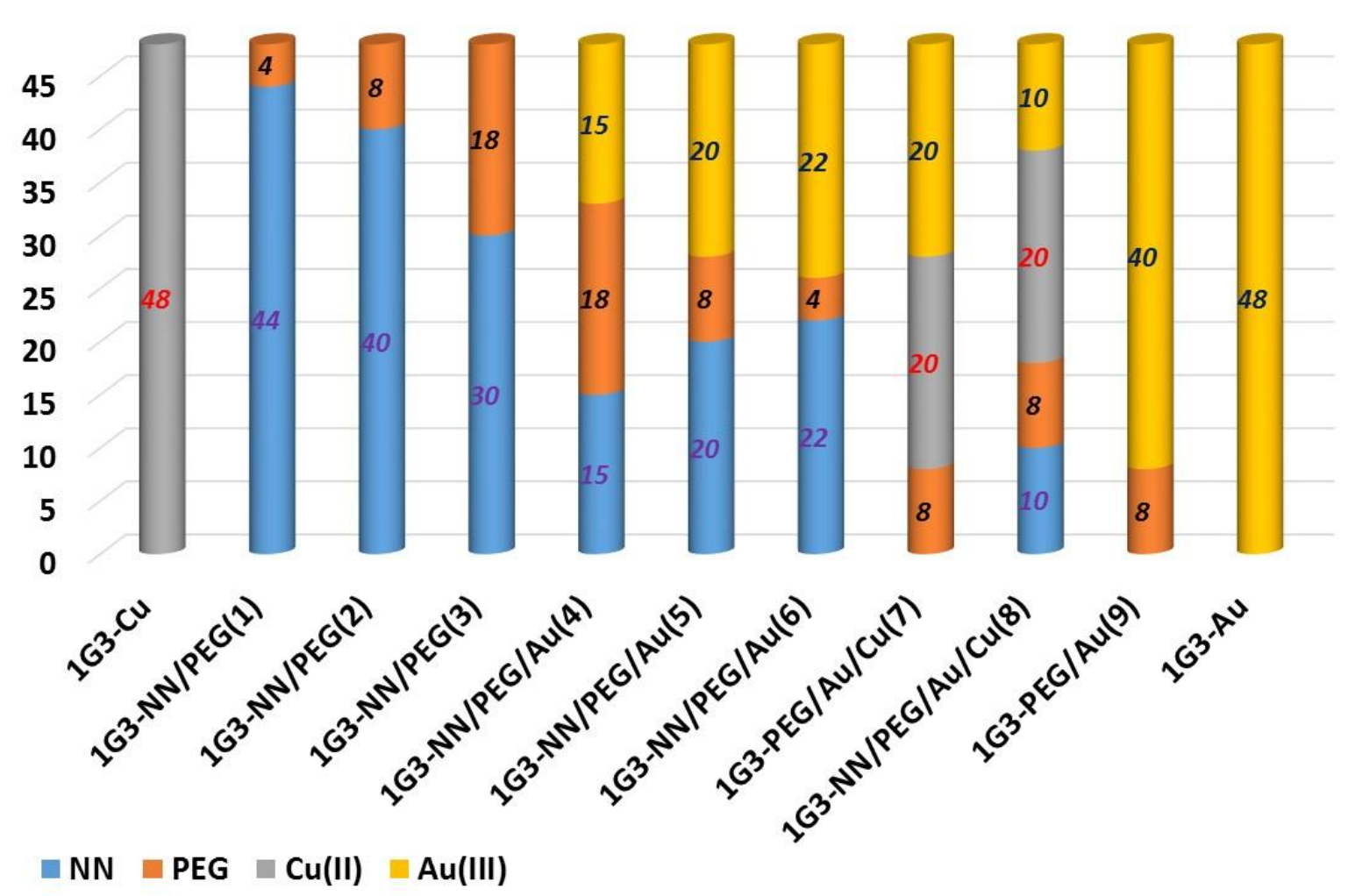

Figure 7. Metal moiety distribution of phosphorus $1 \mathrm{G} 3$ dendrimers. Grey color corresponds to the complexation of the bidentate chelator $N$-(pyridin-2-ylmethylene)ethanamine (NN) grafted on the G3 phosphorus dendrimers and complexed with $\mathrm{Cu}(\mathrm{II})$ metal; blue corresponds to the $\mathrm{N}$-(pyridin-2ylmethylene) ethanamine (NN) grafted on the $\mathrm{G} 3$ phosphorus dendrimer without $\mathrm{Cu}(\mathrm{II})$; yellow color corresponds to the PEG chain ( $11 \mathrm{CH}_{2} \mathrm{CH}_{2} \mathrm{O}$ linkages) grafted on the $\mathrm{G} 3$ phosphorus dendrimers; the yellow color corresponds to the bidentate chelator $N$-(pyridin-2-ylmethylene)ethanamine (NN) grafted on the $\mathrm{G} 3$ phosphorus dendrimers and complexed with $\mathrm{Au}(\mathrm{IIII})$ metal

Table 2. Anti-proliferative activities of 1G3-Cu, 1G3-NN/PEG(1), 1G3-NN/PEG(2), 1G3-NN/PEG(3), 1G3-NN/PEG/Au(4), 1G3-NN/PEG/Au(5), 1G3-NN/PEG/Au(6), 1G3-PEG/Au/Cu(7), 1G3$\mathrm{NN} / \mathrm{PEG} / \mathrm{Au} / \mathrm{Cu}(8), 1 \mathrm{G} 3-\mathrm{PEG} / \mathrm{Au}(9)$ and $1 \mathrm{G} 3-\mathrm{Au}$

\begin{tabular}{|c|c|c|c|}
\hline \multirow[t]{2}{*}{ Dendrimer } & \multicolumn{3}{|l|}{$I C_{50}(n M)$} \\
\hline & KB & HL60 & EPC \\
\hline 1G3-Cu & $470+/-20$ & $580+/-70$ & $800+/-180$ \\
\hline 1G3-NN/PEG(1) & $>1000$ & $>1000$ & $>1000$ \\
\hline 1G3-NN/PEG(2) & $>1000$ & $>1000$ & $>1000$ \\
\hline 1G3-NN/PEG(3) & $>1000$ & $>1000$ & $>1000$ \\
\hline 1G3-NN/PEG/Au(4) & $87+/-7$ & $>1000$ & $>1000$ \\
\hline
\end{tabular}




\begin{tabular}{|l|l|l|l|}
\hline 1G3-NN/PEG/Au(5) & $15+/-5$ & $4.5+/-0.5$ & $>1000$ \\
\hline 1G3-NN/PEG/Au(6) & $6.7+/-4.6$ & $3+/-0.5$ & $>1000$ \\
\hline 1G3-PEG/Au/Cu(7) & $18.5+/-0.7$ & $2.5+/-0.7$ & $>1000$ \\
\hline 1G3-NN/PEG/Au/Cu(8) & $10+/-3$ & $4+/-3$ & $>1000$ \\
\hline 1G3-PEG/Au(9) & $5.5+/-0.5$ & $1.7+/-0.5$ & $>1000$ \\
\hline 1G3-Au & $7.5+/-7.5$ & $3.3+/-0.6$ & $>1000$ \\
\hline
\end{tabular}

\section{Mechanism of actions of $1 \mathrm{G3}$ and $1 \mathrm{G3}-\mathrm{Cu}$}

On the basis of our encouraging results (vide supra), we decided to investigate the mechanism of action of $1 \mathrm{G} 3$ and the corresponding 1G3-Cu by exploring the programmed cell death pathway and the alternative caspase-independent and necrosis pathways (Mignani, El Brahmi, Cresteil \& Majoral, 2018a). Flow cytometry (FACS) analysis (with KB and HL60 tumour cells) demonstrated that 1G3 rapidly induced the entry of cells into early apoptosis, while 1G3-Cu induced massive apoptosis at the same concentration. No activation of the direct necrosis process was observed. Consequently, $1 \mathrm{G} 3$ and 1G3-Cu induced cell death via activation of the apoptotic process. Also, 1G3 was a potent activator of caspase-3, which is the terminal effector of the apoptotic cascade, whereas 1G3-Cu reduced caspase- 3 activity in both KB and HL60 cells at the same concentration: in KB cells, a $5 \mu \mathrm{M}$ treatment for $48 \mathrm{~h}$ resulted in caspase-3 activity of $\sim 160 \%$ for $1 \mathrm{G} 3$ and $\sim 40 \%$ for $1 \mathrm{G} 3-\mathrm{Cu}$. In this study doxorubicin displayed a percent of activation of $\sim 160 \%$, and DMSO (solvent) was $100 \%$. The activation of caspase-3 with $1 \mathrm{G} 3-\mathrm{Cu}$ is not related to the presence of the $\mathrm{CU}(\mathrm{II})$ atom, since copper chloride $\left(\mathrm{CuCl}_{2}\right)$ showed moderate or no inhibitory effect on caspase-3 activity. In addition, immunochemistry studies in the cytosol of KB cells, showed that $1 \mathrm{G} 3$ promoted the conversion of the inactive procaspase- 3 into its active form, whereas 1G3-Cu reduced the content in both active and inactive forms. Consequently, 1G3-Cu induced apoptosis through the caspase-independent pathway, in contrast by $1 \mathrm{G} 3$.

Then, we decided to investigate the mechanism of action of $1 \mathrm{G} 3$ and $1 \mathrm{G} 3-\mathrm{Cu}$ in more depth, particularly the caspase-independent apoptosis pathway. 1G3 caused a moderate reduction of apoptotic inducing factor (AIF) mitochondrial content but increased it in nuclei on a dose-dependent manner. The same effects were observed with 1G3-Cu, but with a higher efficiency, with a complete transfer of AIF from mitochondria to nuclei. Interestingly, 1G3-Cu actively translocated the Bax protein to the mitochondria, promoting AIF release, and finally, induced apoptosis. Bax is a proapoptotic member of the Bcl 2 protein family that is activated and translocated from the cytosol to the mitochondria. With 1G3, moderate translocation of the mitochondrial Bax was observed. Based on the results of dUTP nick-end labelling (TUNEL) technique with fluorescent antibodies, $1 \mathrm{G} 3$ and 1G3-Cu induced considerable augmentation of DNA fragmentation in KB and HL60 cells (24 h exposure, $5 \mu \mathrm{M}$ ): 1G3, KB: 52.9\%, HL60: 16.8\%; 1G3-Cu, KB: 86.2\%, HL60: 78.7\%; Doxorubicin (50 nM), KB: 24.8\%, HL60: 23.4\%; DMSO, KB: 4.1\%, HL60: 9.9\%. 
To our knowledge, this is the first example of nanoparticles in general, and dendrimers in particular, showing potent anti-proliferative activities through Bax protein activation (Figure 8) (Mignani et al., 2017b).

1G3-Cu $\Rightarrow \begin{aligned} & \text { Translocation } \\ & \text { of Baxinto the } \\ & \text { mitochondria }\end{aligned} \Rightarrow \begin{gathered}\text { Release of AIF } \\ \text { into the cytosol }\end{gathered} \Rightarrow \begin{aligned} & \text { Translocation of AIF } \\ & \text { into the nucleus }\end{aligned} \Rightarrow \begin{gathered}\text { DNA fragmentation } \\ \text { without alteration of the } \\ \text { cell cycle }\end{gathered}$
Cell death 4 Apoptosis
$1 \mathrm{G} 3 \Rightarrow \begin{gathered}\text { Activation of the } \\ \text { caspase-3 }\end{gathered}$

Figure 8. Schematic representation of the mechanism of action of $1 \mathrm{G} 3$ and $1 \mathrm{G} 3-\mathrm{Cu}$.

\section{Combination of anti-proliferative efficacy of $1 \mathrm{G3}-\mathrm{Cu}$ with anti-cancer agents}

Solid tumours were tackled by targeted treatments, which generally lead to dramatic regressions; unfortunately, the responses are often short-lived due to major issues, including reversal multidrug resistance (MDR). Other issues include a narrow therapeutic window and the undesired side effects of available anticancer drugs, as well as the limitations of anticancer drugs. To circumvent the MDR effect, the clinical development of multiple therapeutic anticancer agents in combination became the standard of care against many cancer types (Mignani, El Brahmi, Cresteil \& Majoral, 2018b). Based on this precedent and the interesting results with 1G3-Cu showing original induction of caspase-3-independent apoptosis via the translocation of Bax to mitochondria, we decided to investigate the combination of the anti-proliferative efficacy of 1G3-Cu with five anticancer drugs with different modes of action: camptothecin (topoisomerase I inhibitor), cisplatin (alkylating agent that binds to DNA to form intra- and inter-strand cross-links), Taxol (antimitotic agent, 'spindle poison' targets $\beta$-tubulin), MG132 (proteasome inhibitor reduces the degradation of ubiquitinconjugated proteins) and doxorubicin (DNA intercalator, topoisomerase II inhibitor, stabilizes topoisomerase II complex and promotes double-stranded DNA breaks). These combinations were tested in KB and HL60 tumour cell lines at the active dose of each compound. Our strategy is based on the fact that if the inhibition of cell proliferation by the combination of two active compounds does not exceed the inhibition of the most potent one compound in the combination, no additive effect can be concluded, whereas the additive effect would correspond to the sum of the individual inhibitions of each drug, and the synergistic effect would exceed the sum of the inhibition of each single active compound. Table 3 presents the cell proliferation in the presence of $1 \mathrm{G} 3-\mathrm{Cu}$ and anticancer agents alone or in combination in KB and HL60 cell lines. No effect was observed with the combination of 1G3-Cu with camptothecin or cisplatin, except for cisplatin in HL60 cells, whereas an additive effect was observed with 1G3-Cu and paclitaxel or MG132. Interestingly, a synergistic effect was obtained with 1G3-Cu and doxorubicin. 
Table 3. Cell proliferation in the presence of $1 \mathrm{G3}-\mathrm{Cu}$ and anti-cancer agents alone or in combination against KB and $\mathrm{HL} 60$ cell lines. 1G3-Cu: $0.5 \mu \mathrm{M}$

\begin{tabular}{|c|c|c|}
\hline Cells & $\begin{array}{c}\text { Cisplatin } \\
(@ 10 \mu \mathrm{M})\end{array}$ & $\begin{array}{c}\text { Cisplatin } \\
(@ 10 \mu \mathrm{M}) \text { plus } \\
\mathbf{1 G 3 - C u} \\
(@ 0.5 \mu \mathrm{M})\end{array}$ \\
\hline KB & $30.2+/-10.0$ & $40.2+/-12.0$ \\
\hline HL60 & $22.9+/-4.6$ & $45.0+/-7.7$ \\
\hline
\end{tabular}

\begin{tabular}{|c|c|}
\hline $\begin{array}{c}\text { Camptothecin } \\
\text { (@50nM) }\end{array}$ & $\begin{array}{c}\text { Camptothecin } \\
\text { (@50nM) plus } \\
1 \mathrm{G3}-\mathrm{Cu} \\
(@ 0.5 \mu \mathrm{M})\end{array}$ \\
\hline $36.1+/-10.1$ & $55.3+/-11.2$ \\
\hline $48.4+/-6.9$ & $55.8+/-3.9$ \\
\hline
\end{tabular}

\begin{tabular}{|c|c|}
\hline $\begin{array}{c}\text { Paclitaxel } \\
\text { (@0.1nM) }\end{array}$ & $\begin{array}{c}\text { Paclitaxel } \\
\text { (@0.1nM) plus } \\
1 \mathrm{G3}-\mathrm{Cu} \\
(@ 0.5 \mu \mathrm{M})\end{array}$ \\
\hline $60.4+/-8.3$ & $91.1+/-9.3$ \\
\hline $45.4+/-5.1$ & $61.3+/-5.5$ \\
\hline
\end{tabular}

\begin{tabular}{|c|c|c|}
\hline Cells & $\begin{array}{c}\text { Doxorubicin } \\
\text { (@15nM) }\end{array}$ & $\begin{array}{c}\text { Doxorubicin } \\
(@ 15 \mathrm{nM}) \text { plus } \\
1 \mathrm{G3}-\mathrm{Cu} \\
(@ 0.5 \mu \mathrm{M})\end{array}$ \\
\hline KB & $37.0+/-8.5$ & $90.6+/-10.9$ \\
\hline HL60 & $27.5+/-4.9$ & $90.3+/-2.6$ \\
\hline
\end{tabular}

\begin{tabular}{|c|c|}
\hline $\begin{array}{c}\text { MG132 } \\
\text { (50nM) }\end{array}$ & $\begin{array}{c}\text { MG132 } \\
\text { (@50nM) plus } \\
1 \text { G3-Cu } \\
(@ 0.5 \mu M)\end{array}$ \\
\hline $32.0+/-10.3$ & $65.0+/-21.2$ \\
\hline $65.2+/-6.1$ & $90.2+/-1.9$ \\
\hline
\end{tabular}

\section{Conclusion}

In these studies, we outlined the design and the anti-proliferative activity of $\mathrm{Cu}(\mathrm{II})-\mathrm{Au}(\mathrm{III})$ - and mixed $\mathrm{Cu}(\mathrm{II})-\mathrm{Au}(\mathrm{III})$-conjugated phosphorus dendrimers. The most potent is the 1G3-Au(III) dendrimer, which represents a new and promising first-in-class anti-proliferative agent against both solid-tumour and leukemia cell lines. Also, in the copper series, the most potent is $1 \mathrm{G3}-\mathrm{Cu}(\mathrm{II})$, with an original mechanism of action in the nanomedicine domain. $1 \mathrm{G3}-\mathrm{Cu}(\mathrm{II})$ activated the pro-apoptotic Bax protein, a central death regulator that was translocated by $1 \mathrm{G} 3-\mathrm{Cu}(\mathrm{II})$ to the mitochondrial compartment, allowing the release of AIF, and then the activation of the caspase-independent apoptotic pathway. To our knowledge, it is the first example of nanoparticles displaying Bax protein activation and then cell death through apoptosis process. Interestingly, 1G3-Cu(II) showed synergistic effects with doxorubicin. Extension of these studies to $\mathrm{Ru}(\mathrm{II} / \mathrm{III}), \mathrm{Ti}(\mathrm{IV}), \mathrm{Ir}$ and their combination with various antitumoral drugs are under active investigation.

Funding Information

\section{Acknowledgments}


S. Mignani thanks the support of FCT - Fundacão para a Ciência e a Tecnologia with Portuguese Government funds through the CQM Strategic Project PEst-OE/QUI/UI0674/2013, and ARDITIAgência Regional para o Desenvolvimento da Investigação Tecnologia through the project M142001-0145-FEDER-000005 - Centro de Química da Madeira - CQM+ (Madeira 14-20 Program). J. P. Majoral and A.-M Caminade thank the CNRS (France) for financial support. L. Chen thanks CSC for a PhD grant.

Notes

The authors declare no competing financial interest.

References

Allen, C. (2016) Why I'm holding onto hope for nano in oncology. Molecular Pharmaceutics, 13, 2603-2604.

Amin, L. (2013) P-glycoprotein Inhibition for Optimal Drug Delivery. Drug Target Insights, 7, 27-34.

Blanco, E., Shen, H. \& Ferrari, M. (2015) Principles of nanoparticle design for overcoming biological barriers to drug delivery. Nature Biotechnology, 33, 941-951.

Bourzac, K. (2012) Nanotechnology: Carrying drugs. Nature, 491(7425), S58-S60.

Caminade A. M. (2017) Phosphorus dendrimers for nanomedicine. Chemical Communications, 53, 9830-9838.

Caminade, A. M., Fruchon, S., Turrin, C. O., Poupot, M., Ouali, A., Maraval, A., ... Poupot R. (2015) The key role of the scaffold on the efficiency of dendrimer nanodrugs. Nature Communications, 6 , 7722.

Caminade, A. M., Turrin, C. O. \& Majoral J. P. (Eds) (2018) Phosphorus dendrimers in biology and nanomedicine, Pan Standford Publishing, Singapore.

Chauhan, V. P. \& Jain, R. K. (2013) Strategies for advancing cancer nanomedicine. Nature Materials, $12,958-962$.

Chemotherapy Procedure - Information \& Support. Available at https://www.canteen.org.au/cancer-information/treatments-and-sideeffects/treatments/chemotherapy/ [Accessed April 2019].

El Brahmi, N., El Kazzouli, S., Mignani, S. M., Essassi, E., Aubert, G., Laurent, R., ... Majoral, J. P. (2013) Original Multivalent Copper(II)-Conjugated Phosphorus Dendrimers and Corresponding Mononuclear Copper(II) Complexes with Antitumoral Activities. Molecular Pharmaceutics, 10, 14591464.

El Kazzouli, S., El Brahmi, N., Mignani, S., Bousmina, M., Zablocka, M. \& Majoral, J. P. (2012) From Metallodrugs to Metallodendrimers for Nanotherapy in Oncology: A Concise Overview. Current Medicinal Chemistry, 19, 4995-5010. 
Ferrari, M. (2005) Cancer nanotechnology: Opportunities and challenges. Nature Review Cancer, 5, 161-171.

Holohan, C., Van Schaeybroeck, S., Longley, D. B. \& Johnston, P. G. (2013) Cancer drug resistance: An evolving paradigm. Nature Review Cancer, 13, 714-726.

Kannan, R. M., Nance, E., Kannan, S. \& Tomalia, D. A. (2014) Emerging concepts in dendrimer-based nanomedicine: from design principles to clinical applications. Journal of Internal Medicine, 276, 579617.

Kartalou, M. \& Essigmann, J. M. (2001) Mechanisms of resistance to cisplatin. Mutation Research, $478,23-43$.

Kim, J., Yoon, H-J., Kim, S., Wang, K., Ishii, T., Kim, Y-R., Jang, W-D., (2009) Polymer-metal complex micelles for the combination of sustained drug releasing and photodynamic therapy. J. Mater. Chem. $19,4627-4631$.

Lehne, G. (2000) P-glycoprotein as a drug target in the treatment of multidrug resistant cancer. Current Drug Targets, 1, 85-99.

Medina, S. H. \& El-Sayed, M. E. H. (2009) Dendrimers as Carriers for Delivery of Chemotherapeutic Agents. Chemical Reviews, 109, 3141-3157.

Mignani, S., El Brahmi, N., Cresteil, T. \& Majoral, J. P. (2018a) First-in-class anti-cancer nanoparticle copper(II) phosphorus dendrimers as pro-apoptotic Bax activators. Phosphorus dendrimers in biology and nanomedicine, Caminade, A. M., Turrin, C. O. \& Majoral, J. P. (Eds) Pan Standford Publishing, Singapore.

Mignani, S., El Brahmi, N., Cresteil, T. \& Majoral, J. P. (2018b) First-in-Class Combination Therapy of a Copper(II) Metallo-Phosphorus Dendrimer with Cytotoxic Agents. Oncology, 94, 324-332.

Mignani, S., El Kazzouli, S., Bousmina, M. \& Majoral, J. P. (2013a) Expand classical drug administration ways by emerging routes using dendrimer drug delivery systems: a concise overview. Advances in Drug Delivery Reviews, 65,1316-1330.

Mignani, S., El Kazzouli, S., Bousmina, M. M. \& Majoral, J. P. (2013b) Dendrimer space concept for innovative nanomedicine: A futuristic vision for medicinal chemistry. Progess in Polymer Science, 38, 3626-3629.

Mignani, S. \& Majoral, J. P. (2013) Dendrimers as macromolecular tools to tackle from colon to brain tumor types: a concise overview, New Journal of Chemistry, 37, 3337-3357.

Mignani, S., Rodrigues, J., Tomas, H., Zablocka, M., Shi, X., Caminade, A. M. \& Majoral, J. P. (2018) Dendrimers in combination with natural products and analogues as anti-cancer agents. Chemical Society Reviews, 47, 514-532.

Mignani, S. M., El Brahmi, N., El Kazzouli, S., Laurent, R., Ladeira, S., Caminade, A. M. ... Majoral, J. P. (2017a) Original Multivalent Gold(III) and Dual Gold(III)-Copper(II) Conjugated Phosphorus 
Dendrimers as Potent Antitumoral and Antimicrobial Agents. Molecular Pharmaceutics, 14, 40874097.

Mignani, S. M., El Brahmi, N., Eloy, L., Poupon, J., Nicolas, V., Steinmetz, A., ... Cresteil T. (2017b) Anticancer copper(II) phosphorus dendrimers are potent proapoptotic Bax activators. European Journal of Medicinal Chemistry, 132, 142-156.

Ottaviani, M. F., El Brahmi, N., Cangiotti, M., Coppola, C., Buccella, F., Cresteil, T., ... Majoral J.P. (2014) Comparative EPR Studies of Cu (II)-conjugated Phosphorous-Dendrimers in the Absence and Presence of Normal and Cancer Cells. RSC Advances, 4, 36573-36583.

Petros, R. A. \& De Simone, J. M. (2010) Strategies in the design of nanoparticles for therapeutic applications. Nature Reviews Drug Discovery, 9, 615-627.

Rolland, O., Turrin, C. O., Caminade, A. M. \& Majoral, J. P. (2009) Dendrimers and nanomedicine: multivalency in action. New Journal of Chemistry, 33, 1809-1824.

Slany, M., Bardaji, M., Casanove, M. J., Caminade, A. M., Majoral, J. P. \& Chaudret, B. (1995) Dendrimer surface chemistry. An easy access to poly phosphines and their gold complexes. Journal of the American Chemical Society, 117, 9764-9765.

Sourdon, A., Gary-Bobo, M., Maynadier, M., Garcia, M., Majoral, J. P., Caminade, A. M., Mongin, O. \& Blanchard-Desce, M. (2019) Dendrimeric nanoparticles for two-photon photodynamic therapy and imaging: synthesis, photophysical properties, innocuousness in daylight and cytotoxicity under twophoton irradiation in the NIR. Chemistry- A European Journal, 25, 3637-3649.

Starpharma. https://starpharma.com/ [Accessed April 2019].

Further Reading 